\title{
Hexobarbital Sleep Test for Predicting the Susceptibility or Resistance to Experimental Posttraumatic Stress Disorder
}

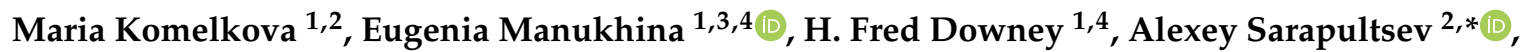 \\ Olga Cherkasova ${ }^{5}{ }^{\circ}$, Viacheslav Kotomtsev ${ }^{2,6}$, Pavel Platkovskiy ${ }^{7}$, Stanislav Fedorov ${ }^{7}$, \\ Petr Sarapultsev ${ }^{2}$, Olga Tseilikman ${ }^{1,7}$, David Tseilikman ${ }^{7}$ and Vadim Tseilikman ${ }^{1}$ \\ 1 School of Medical Biology, South Ural State University, 454080 Chelyabinsk, Russia; \\ mkomelkova@mail.ru (M.K.); manukh@mail.ru (E.M.); Fred.Downey@unthsc.edu (H.F.D.); \\ diol2008@yandex.ru (O.T.); vadimed@yandex.ru (V.T.) \\ 2 Institute of Immunology and Physiology, Ural Division of the Russian Academy of Sciences, \\ 620049 Ekaterinburg, Russia; 2134012@gmail.com (V.K.); p.sarapultsev@gmail.com (P.S.) \\ 3 Laboratory for Regulatory Mechanisms of Stress and Adaptation, Institute of General Pathology and \\ Pathophysiology, 125315 Moscow, Russia \\ 4 Department of Physiology and Anatomy, University of North Texas Health Science Center, \\ Fort Worth, TX 76107, USA \\ 5 Biophysics Laboratory, Institute of Laser Physics, Siberian Branch of the Russian Academy of Science, \\ 630090 Novosibirsk, Russia; cherk_63@mail.ru \\ 6 Laboratory of Biomedical Research, Ural Research Institute for Phthisiopulmonology of ministry of Health \\ of Russian Federation, 620039 Ekaterinburg, Russia \\ 7 Department of Fundamental Medicine, Chelyabinsk State University, 454001 Chelyabinsk, Russia; \\ f.schwarcz@yandex.ru (P.P.); fedorovstas2016@yandex.ru (S.F.); tceilikmanve@susu.ru (D.T.) \\ * Correspondence: a.sarapultsev@gmail.com; Tel.: +7-912-03-21691
}

Received: 19 June 2020; Accepted: 14 August 2020; Published: 17 August 2020

Abstract: Hexobarbital sleep test (HST) was performed in male Wistar rats (hexobarbital $60 \mathrm{mg} / \mathrm{kg}$, i.p.) 30 days prior to stress exposure. Based on the duration of hexobarbital-induced sleep, rats were divided into two groups, animals with high intensity (fast metabolizers (FM), sleep duration $<15 \mathrm{~min}$ ) or low intensity of hexobarbital metabolism (slow metabolizers (SM), sleep duration $\geq 15 \mathrm{~min}$ ). The SM and FM groups were then divided into two subgroups: unstressed and stressed groups. The stressed subgroups were exposed to predator scent stress for 10 days followed by 15 days of rest. SM and FM rats from the unstressed group exhibited different behavioral and endocrinological patterns. SM showed greater anxiety and higher corticosterone levels. In stressed animals, anxiety-like posttraumatic stress disorder (PTSD) behavior was aggravated only in SM. Corticosterone levels in the stressed FM, PTSD-resistant rats, were lower than in unstressed SM. Thus, HST was able to predict the susceptibility or resistance to experimental PTSD, which was consistent with the changes in glucocorticoid metabolism.

Keywords: hexobarbital sleep test; posttraumatic stress disorder; corticosterone; glucocorticoid metabolism; resilience

\section{Introduction}

Posttraumatic stress disorder (PTSD) is a severe mental disorder that develops in people exposed to trauma [1]. PTSD is a delayed response to a traumatic event following a prolonged latent period [1,2]. This latent period provides an opportunity for treatment to lessen subsequent PTSD or perhaps even prevent it. For this approach to be efficient, it would be valuable to predict which persons exposed 
to trauma are PTSD-susceptible, but at present, this capability does not exist. Importantly, only about $20 \%$ of traumatized subjects develop PTSD [3]. Therefore, people may be PTSD-susceptible or PTSD-resistant.

Recently, we showed that a hexobarbital sleep test (HST) could predict in which rats a halogenated glucocorticoid, triamcinolone acetonide, would produce a side effect of elevated anxiety [4]. From the duration of hexobarbital-induced sleep, the HST identified rats with high or low intensity of microsomal oxidation (fast or slow metabolizers, FM, or SM) and, thus, predicted their anxiety response to the exogenous glucocorticoid. Another known side effect of this drug is the suppressed production of endogenous glucocorticoids due to adrenal gland dystrophy [5]. The development of PTSD symptoms, including anxiety [1], is preceded by prolonged, stress-induced exposure to high levels of glucocorticoids [6], which eventually results in exhaustion and dystrophy of the adrenal glands and decreased glucocorticoid production [7].

Since the consequences of exogenous and stress-induced high concentrations of glucocorticoids are similar, it appeared that the HST might be capable of predicting individual rat vulnerability or resistance to PTSD. Our approach was to compare the behavioral and hormonal responses of rats exposed to traumatic stress with their hexobarbital sleep time.

Earlier, we showed that FM and SM phenotypes differ in the intensity of microsomal oxidation and the resulting levels of glucocorticoids [4,8]. Glucocorticoids are metabolized via two major pathways, by cytochrome P4503A (CYP3A), which depends on microsomal oxidation) and by 11ß-hydroxysteroid dehydrogenase type 2 (11ßHSD-2), which does not depend on microsomal oxidation). However, to demonstrate that these phenotypes were, indeed, present in this study and associated with vulnerability or resistance to PTSD, we confirmed that FM and SM rats used different metabolic pathways to metabolize glucocorticoids. For this reason, not only corticosterone, but also the markers of CYP3A-dependent and 11ßHSD-2 dependent glucocorticoid metabolic pathways, were measured.

\section{Results}

\subsection{Effect of Microsomal Oxidation Phenotype and Predator Stress on Rats Behavior}

Behavioral data are reported in Table 1. Two-way ANOVA showed the effect of the microsomal oxidation phenotype on the behavior of FM and SM rats. The presence of statistically significant differences in the time spent in the open (F1.62 $=22.86: p<0.001)$ and closed $(\mathrm{F} 1.62=22.86: p<0.001)$ arms, as well as on the number of entries into the open (F1.62 $=19.88: p<0.001)$ and closed (F1.62 $=3.95$ : $p<0.05)$ arms of the elevated plus-maze, was revealed. In unstressed FM rats, the time spent and the number of entries into open arms were higher than in unstressed SM rats $(p=0.038$ and $p=0.025$, respectively). On the contrary, the time spent and the number of entries into closed arms in unstressed FM were lower in comparison to unstressed SM rats (respectively, $p=0.038$ and $p=0.034$ ).

According to two-way ANOVA, stress had a significant impact on the time spent in the open (F1.62 $=6.63: p=0.012)$ and in closed (F1.62 $=6.95: p=0.011)$ arms, as well as on the number of entries into the open (F1.62 $=6.63: p=0.012)$ and closed $(\mathrm{F} 1.62=22.34: p<0.001)$ arms of the elevated plus-maze. Stressed FM rats have revealed an increase in time spent $(p<0.001)$ and a number of visits $(p=0.002)$ into open arms, and the decrease in time spent in closed arms $(p<0.001)$ of the elevated plus-maze in comparison to control FM animals. Stressed FM and SM rats have displayed an increase in the number of entries into closed arms compared with the corresponding controls $(p=0.003$ and $p<0.001$ ) was also detected in stressed FM and SM rats.

The significant effect of the microsomal oxidation phenotype on the anxiety index (AI) value (F1.62 $=22.33: p<0.001$ ) was revealed. The unstressed FM rats had lower AIs in comparison to unstressed SM rats $(p=0.04)$ and stress further reduced AIs in FM rats $(p=0.003)$ with no effect on SM rat's AIs. The AI significantly correlated with HST time $(\mathrm{r}=0.83 ; p<0.01 ; n=62)$. 
Table 1. Laboratory indicators and behavior of fast metabolism (FM) and slow metabolism (SM) rats.

\begin{tabular}{|c|c|c|c|c|}
\hline & \multicolumn{2}{|c|}{ FM $(n=42)$} & \multicolumn{2}{|c|}{$\mathrm{SM}(n=20)$} \\
\hline & $\begin{array}{l}\text { Unstressed } \\
\quad(n=22)\end{array}$ & $\begin{array}{l}\text { Stressed } \\
(n=20)\end{array}$ & $\begin{array}{l}\text { Unstressed } \\
\quad(n=8)\end{array}$ & $\begin{array}{l}\text { Stressed } \\
(n=12)\end{array}$ \\
\hline Time in open arms, s & $154.2 \pm 24.6$ & $258.5 \pm 19.6^{* * *}$ & $78.5 \pm 16.6 \#$ & $100.2 \pm 21.4$ \#\#\# \\
\hline Time in closed arms, s & $445.8 \pm 24.6$ & $341.5 \pm 19.6^{* * *}$ & $521.5 \pm 16.6 \#$ & $499.8 \pm 21.4$ \#\#\# \\
\hline Entries into open arms & $6.3 \pm 0.6$ & $8.7 \pm 0.4^{* *}$ & $4.2 \pm 0.5 \#$ & $5.2 \pm 0.6 \# \# \#$ \\
\hline Entries into closed arms & $7.8 \pm 0.8$ & $10.6 \pm 0.5^{* *}$ & $5.4 \pm 0.6 \#$ & $10.0 \pm 0.9^{* *}$ \\
\hline Anxiety index & $0.65 \pm 0.02$ & $0.56 \pm 0.02 * *$ & $0.71 \pm 0.02 \#$ & $0.74 \pm 0.02 \# \# \#$ \\
\hline Grooming & $2.91 \pm 0.55$ & $2.63 \pm 0.47$ & $1.0 \pm 0.3$ & $2.5 \pm 0.42$ \\
\hline Cort, $\mathrm{nM} / \mathrm{l}$ & $197.4 \pm 18.6$ & $135.0 \pm 13.1^{*}$ & $270.4 \pm 37.1 \#$ & $154.3 \pm 25.3^{* *}$ \\
\hline 11Dehydro Cort, nM/l & $1.3 \pm 0.2$ & $3.6 \pm 0.8$ & $5.5 \pm 1.6 \# \# \#$ & $6.5 \pm 1.9$ \\
\hline $6 \beta$ Cort in liver, $\mathrm{nM} / \mathrm{g}$ & $0.28 \pm 0.01$ & $0.25 \pm 0.02$ & $0.14 \pm 0.04 \# \#$ & $0.24 \pm 0.04 *$ \\
\hline $6 \beta$ Cort in blood, $n M / 1$ & $0.39 \pm 0.05$ & $0.65 \pm 0.1^{* *}$ & $0.45 \pm 0.04$ & $0.52 \pm 0.03$ \\
\hline $11 \beta \mathrm{HSD}-2, \mathrm{nmol}$ min-1 g-1 & $9.73 \pm 0.46$ & $10.07 \pm 0.94$ & $13.45 \pm 0.67 \# \#$ & $11.26 \pm 0.96$ \\
\hline
\end{tabular}

Values are means \pm SE. ${ }^{*}$ Significantly different from unstressed rats; ${ }^{*} p<0.05 ;{ }^{* *} p<0.01 ;{ }^{* * *} p<0.001$. \# Significantly different from fast metabolizers; $\# p<0.05$; \#\# $p<0.01$; \#\# $p<0.001$.

According to two-way ANOVA, there were no significant differences in grooming (F1.62 = 3.45: $p=0.07)$, but the clear upward trend toward an increase in the number of grooming acts was detected in stressed SM rats.

\subsection{Effect of Microsomal Oxidation Phenotype and Predator Stress on Plasma Corticosterone Concentration}

According to two-way ANOVA, the FM or SM phenotype exerted significant effects on concentrations of blood corticosterone (F1.62 $=4.38: p=0.041$, Table 1). Concentrations of corticosterone were higher in unstressed SM than unstressed FM rats $(p=0.028)$.

Two-way ANOVA showed that stress exerted significant effects on corticosterone (F1.62 = 16.37: $p<0.001)$. Plasma concentration of corticosterone was lower both in stressed FM $(p=0.019)$ and SM $(p=0.002)$ rats in comparison to control animals.

Moreover, plasma corticosterone concentration significantly correlated with the number of entries in open arms ( $\mathrm{r}=-0.65 p<0.05 ; n=8)$ and with grooming $(\mathrm{r}=0.79 ; p<0.05 ; n=8)$ in unstressed SM rats.

\subsection{Effect of Microsomal Oxidation Phenotype and Predator Stress on Corticosterone Metabolites Concentrations}

According to two-way ANOVA, microsomal oxidation phenotype exerted significant effects on corticosterone metabolites concentrations (i.e., 11DehydroCort in blood $(\mathrm{F} 1.62=10.98: p=0.002)$ and $6 \beta$ Cort in liver (F1.62 $=7.19: p=0.01$ ) (Table 1$)$.

Concentration of 11Dehydro Cort was higher in unstressed SM than unstressed FM rats $(p=0.009)$. The hepatic level of $6 \beta$ Cort was lower in unstressed SM than unstressed FM rats $(p=0.002)$. Plasma 11Dehydro Cort concentration significantly correlated with number of entries in close arms $(\mathrm{r}=-0.94$ $p<0.05 ; n=8)$, with grooming $(\mathrm{r}=0.91 ; p<0.05 ; n=8)$ in unstressed SM rats. Hepatic $6 \beta$ Cort significantly correlated with grooming $(\mathrm{r}=-0.45 p<0.05 ; n=22)$ in unstressed FM rats.

Two-way ANOVA showed, that stress exerted significant effects on 6 $\beta$ Cort $(\mathrm{F} 1.62=7.69: p=0.009)$ concentration in blood. In FM animals, stress caused an increase in $6 \beta$ Cort concentration in blood $(p=0.004)$. With that, stress did not affect the concentration of 11Dehydro Cort in the blood of rats with SM and FM phenotypes.

Thus, it can be concluded that CYP3A-dependent glucocorticoid metabolism predominated in FM rats, while 11ßHSD-dependent metabolism predominated in SM rats. Exposure to stress did not cause any fundamental changes in the type of glucocorticoid metabolism. 


\subsection{Effect of Microsomal Oxidation Phenotype and Predator Stress on Kidneys 11BHSD-2 Activity}

According to two-way ANOVA, both phenotypes exerted significant effects on kidney 11ßHSD-2 $($ F1.62 $=7.23: p=0.009)$. Kidney 11ßHSD-2 activity was higher in unstressed SM than unstressed FM rats $(p=0.01)$. Notably that kidney $11 \beta$ HSD-2 activity significantly correlated with times spent in open arms ( $\mathrm{r}=-0.94 p<0.01 ; n=8)$, with times spent in closed arms $(\mathrm{r}=0.91 ; p<0.01 ; n=8)$ with number of entries in the open arms $(\mathrm{r}=-0.83 p<0.05 ; n=8)$ and with $\mathrm{AI}(\mathrm{r}=0.94 ; p<0.01 ; n=8)$ in unstressed SM rats.

\section{Discussion}

Previously, predator scent stress (PSS) has been shown to produce PTSD anxiety-like behavior in rats [9]. In the current study, rats were divided into two groups, animals with high intensity (fast metabolizers, FM, sleep duration $<15 \mathrm{~min}$ ) or with low intensity of hexobarbital metabolism (slow metabolizers, $\mathrm{SM}$, sleep duration $\geq 15 \mathrm{~min}$ ), and, according to the results, the unstressed SM rats had an average $\mathrm{AI}=0.71$, whereas the $\mathrm{AI}$ of unstressed $\mathrm{FM}$ had an average $\mathrm{AI}=0.65$. Moreover, stress has further reduced AIs in FM rats $(p=0.003)$ with no effect on SM rat's AIs. Thus, one can conclude that HST was able to reveal rats predisposed to PTSD.

PPS has led to a decrease in corticosterone levels in both phenotypes. This is consistent with previously reported results, where a similar decrease in the blood corticosterone in rats exposed to traumatic stress was observed [7].

Importantly, unstressed SM and FM rats differed in their glucocorticoid metabolism. Unstressed FM had a lower level of corticosterone than SM rats, which was consistent with our previous data $[4,8]$. Effects of PTSD on plasma corticosterone/cortisol have been studied on different PTSD models and in clinical studies. Some PTSD models induced an increase in plasma corticosterone, such as single and done-twice predator stress [10,11]. Furthermore, Wilson et al. (2013) observed both elevated adrenal corticosterone production and adrenal gland hypertrophy [12]. Other studies have reported reduced plasma concentrations of corticosterone in rats and of cortisol in humans, which is considered an important marker of PTSD $[13,14]$. In our study, experimental PTSD was induced by chronic predator stress with multiple stress exposures rather than single acute exposure, which was apparently the reason for reduced plasma corticosterone.

In the present study, we addressed the influence of the CYP3A-dependent part of glucocorticoid metabolism activity on the formation of susceptibility or resistance to experimental PTSD. Previously, it was shown that fast metabolizers (FM) are characterized by an increased level of CYP3A activity [4]. However, the method used for determining the enzymatic activity did not involve a direct evaluation of glucocorticoid metabolites, which reduced its information value. The direct evaluation of $6 \beta$ Cort allowed us to evaluate the glucocorticoid metabolism by the CYP3A pathway. With that, the more pronounced decrease in corticosterone in stressed SM rats was observed in comparison to FM rats. This pronounced decrease was due to the initially higher basal levels of the 11ßHSD-2 and moderate activation of the CYP3A-dependent pathway enzymes, which was confirmed by the elevated levels of $6 \beta$ Cort in the liver.

At the same time, the unstressed SM rats had higher levels of 11Dehydro Cort, which indicated the activation of $11 \beta H S D$-dependent glucocorticoid metabolism, as 11Dehydro Cort is a product of glucocorticoid C11-oxidation (Figure 1). 


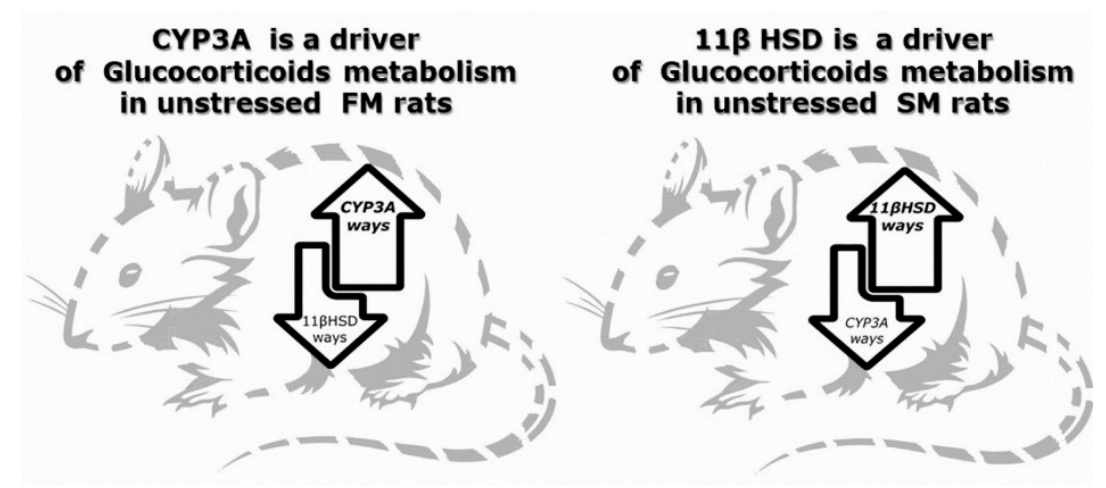

Figure 1. Key pathways of glucocorticoid tissue metabolism of in fast (FM) and slow (SM) metabolizers.

The unstressed FM and SM rats differed in the intensity of CYP3A and 11ßHSD-2 reactions, since CYP3A is an enzyme of the irreversible, whereas 11ßHSD-2 is an enzyme of the reversible pathway of glucocorticoid inactivation, and can be involved in the regulation of glucocorticoid recovery via $11 \beta$ HSD-1 $[15,16]$. With that, PTSD is known to be characterized by an activated $11 \beta H S D-2$ pathway of corticosterone metabolism [2], and thus this feature of glucocorticoid metabolism, along with more pronounced anxiety points at "slow metabolism", as a risk factor for PTSD.

In general, the initially low glucocorticoid level in FM rats may contribute to the development of resistance to behavioral disorders $[17,18]$. It is noteworthy that SM rats with an initially higher level of corticosterone demonstrate higher anxiety and, accordingly, are more prone to the development of behavioral disorders. With that, glucocorticoids are inducers of CYP3A expression and therefore, it is paradoxical that despite the higher basal level of corticosterone, unstressed SM rats are not characterized by the activation of the CYP3A pathway. Probably, the inhibition of the CYP3A pathway in this phenotype is caused by other mechanisms, which can involve the action of proinflammatory cytokines or disturbances in serotonin turnover. Meanwhile, in rats with the high anxiety phenotype, a decrease in serotonin levels in various regions of the brain was observed in this PTSD model [19]. It is possible that elevated levels of $6 \beta$ Cort in stressed SM rats were associated with that previously detected decrease in the level of cerebral serotonin. Moreover, a more pronounced decrease in corticosterone levels in stressed SM rats could enhance the effects of pro-inflammatory cytokines up to neuroinflammation [20], and thus could contribute to the higher anxiety in those rats.

The feasibility of using HST for the early detection of animals susceptible and resistant to PTSD has been reported previously [21]. However, early results could not explain why HST, being the simple pharmacological test, was effective in predicting anxiety disorders.

This study has revealed the dominance of $11 \beta$ HSD-2 dependent glucocorticoid metabolism in SM rats. Particularly impressive are the obtained positive correlations between the activity of 11ßHSD-2 in the kidneys and indicators of anxiety behavior in the elevated plus-maze test. This opens up new ways for the translation of the results to the clinic. The impossibility of using HST in humans is obvious. However, one can assess the prospect of using 11-dehydrocorticosterone in the blood to predict the development of PTSD long before the traumatic event.

\section{Materials and Methods}

Experiments were performed on 62 Wistar male rats weighing 220-263 g. Animals were housed in standard conditions, exposed to a 12:12 h light-dark cycle, and received food and water ad libitum. All animal procedures were performed in accordance with the U.S. National Research Council Guide for the Care and Use of Laboratory Animals 2011. The experimental protocols were approved by the Ethical Committee for Animal Experiments of Institute of Immunology and Physiology, Ural Division of the Russian Academy of Sciences (\# 3001-sar02-2018, Ekaterinburg, Russian Federation). The number of animals was determined based on previous studies $[4,8,22]$ 
The hexobarbital solution was prepared on the day of the experiment and administered i.p. at a dose of $60 \mathrm{mg} / \mathrm{kg} 30$ days prior to traumatic stress. The sleep time after hexobarbital (HST) administration was designated as the time between the injection of hexobarbital and recovery of the righting reflex. The righting reflex was defined as the ability of the animal, after being placed on its back on a flat surface, to turn over by $180^{\circ}$ three times within $15 \mathrm{~s}$ (Figure 2).

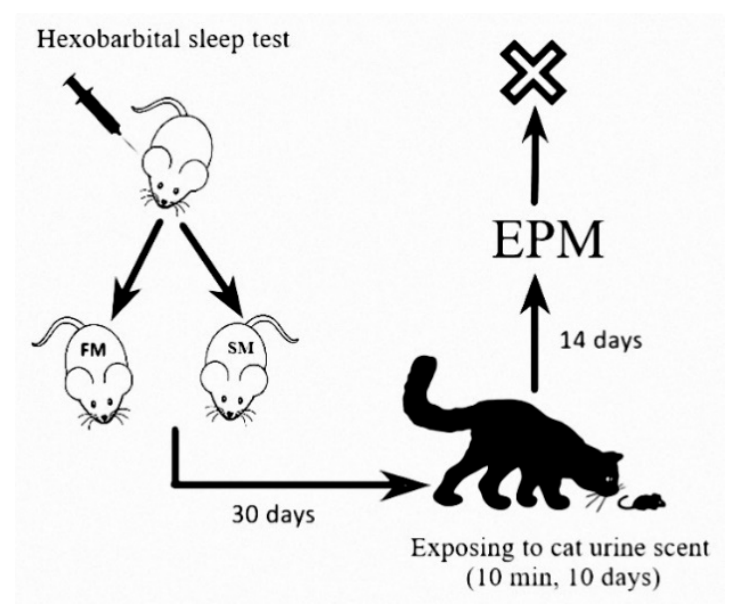

Figure 2. Experimental design. EPM—elevated plus maze test.

Based on the results of the HST test, rats were divided into two groups: FM (sleep duration $<15 \min , n=42,68 \%$ of the study subjects) and SM (sleep duration $\geq 15 \mathrm{~min}, n=20,32 \%$ of the study subjects), reflecting the intensity of microsomal oxidation $[4,8]$. This ratio is consistent with the ratio of PTSD-resistant and PTSD-vulnerable rats in the total population observed in our previous study, and humans exposed to a traumatic event $[19,23]$

The FM and SM groups were then divided into unstressed and stressed groups. Unstressed rats rested throughout this period. The stressed subgroups were exposed to cat urine scent (PSS) for $10 \mathrm{~min}$ daily for 10 days followed by 14 days of rest under stress-free conditions [24].

The behavior of all rats was evaluated with an elevated plus maze test, using the standard elevated plus maze (EPM) test apparatus TS0502-R3 (OpenScience, Russia). Recorded variables included the time spent in open and closed arms of the maze and the number of entries into the open and closed arms $[25,26]$. The video system SMART with SMART 3.0 software was used. Based on these measurements, an anxiety index [27] was calculated: $\mathrm{AI}=1-\{[($ time in open arms/time on maze $)+$ (number of entries into open arms/number of all entries)]/2\}.

Between 11.00 a.m. and 1.00 p.m. on the day following the behavioral test, rats were sacrificed by decapitation under ether anesthesia, and samples of trunk blood and adrenal glands were collected. Blood was transferred to sterile glass tubes containing K2 EDTA, rotated, and centrifuged at $40{ }^{\circ} \mathrm{C}$ and $3000 \mathrm{~g}$ for $10 \mathrm{~min}$. Plasma was separated into aliquots, which were frozen at $-80 \mathrm{C}$ for subsequent measurement of corticosterone.

Plasma and liver $6 \beta$-hydroxycorticosterone (6ßCort), a marker of glucocorticoid metabolism, were measured using a rat 6 beta-hydroxycorticosterone ( 6 beta-OH-B) ELISA kit (Blue Gene Biotech, Shanghai, China) according to the manufacturer's instruction. The assay sensitivity was $1.0 \mathrm{ng} / \mathrm{mL}$, and the intra- and inter-assay coefficients of variation were both $<5 \%$.

Corticosterone (4-pregnen-11 $\beta, 21$-diol-3,20-dione) and 11-dehydrocorticosterone (21-hydroxypregn-4-ene-3,11,20-trione) (Koch-Light Laboratories Ltd., Haverhill, Suffolk, UK) were used. Standard solutions of corticosteroids $(1 \mathrm{mg} / \mathrm{mL})$ were prepared using ethyl alcohol. The working solutions of corticosteroid hormones in the concentration from 2 to $50 \mathrm{ng} / \mu \mathrm{L}$ were prepared from the standard solutions by a corresponding dilution with ethyl alcohol. 
Determination of corticosteroid hormones in rat blood plasma was carried out using micro-column high-performance liquid chromatography (HPLC). Milikhrom-1 chromatograph (NPO Nauchpribor, Orel, Russia) was used in the work. The chromatograph was equipped with a stainless-steel chromatographic column $(2 \times 62 \mathrm{~mm}$, Silasorb C18 SPH $(5 \mu \mathrm{m}))$. Gradient elution was carried out with acetonitrile in water from 30 to $55 \%(v / v)$. The eluent flow rate was $100 \mu \mathrm{L} / \mathrm{min}$. Detection was carried out at two wavelengths: 240 and $260 \mathrm{~nm}$. These wavelengths were chosen in accordance with the absorption spectrum of steroid hormones: $240 \mathrm{~nm}$ is the wavelength corresponding to the maximal absorption of the majority of corticosteroid hormones, while $260 \mathrm{~nm}$ is the wavelength at which the absorption is about a half of the maximal level. Chromatographic information was processed with the help of CHROM software (EcoNova, Institute of Chromatography, Novosibirsk, Russia). Hormone identification was performed by comparing retention times and spectral ratios of endogenous corticosteroid hormones and synthetic preparations.

The treatment of blood plasma. Extraction of corticosteroid hormones from blood plasma was carried out according to the procedure described previously [28], namely, $0.5 \mathrm{~mL}$ of blood plasma, $0.5 \mathrm{~mL}$ of water were poured in glass tubes $15 \mathrm{~mL}$ in volume. Then, $4 \mathrm{~mL}$ of hexane was added, and the tubes were stirred for $3 \mathrm{~min}$. After that, the organic layer was removed using a water-jet pump. Then, $9 \mathrm{~mL}$ of chloroform was added to the aqueous phase, and extraction was carried out for $5 \mathrm{~min}$. The aqueous layer was removed with a water-jet pump, and the organic layer was evaporated in portions in conical plastic tubes under the flow of nitrogen at a temperature of $40{ }^{\circ} \mathrm{C}$. The residue was dissolved in $24 \mu \mathrm{L}$ of a $55 \%$ solution of $\mathrm{CH} 3 \mathrm{CN}$ in water and thoroughly mixed. The portion taken for the chromatographic analysis was $8 \mu \mathrm{L}$ of the extract. The amount of corticosteroid hormones was determined in the units of nanograms per $1 \mathrm{~mL}$ of blood plasma $(\mathrm{ng} / \mathrm{mL})$. The chromatogram of rat blood plasma extract is shown in Figure 3.

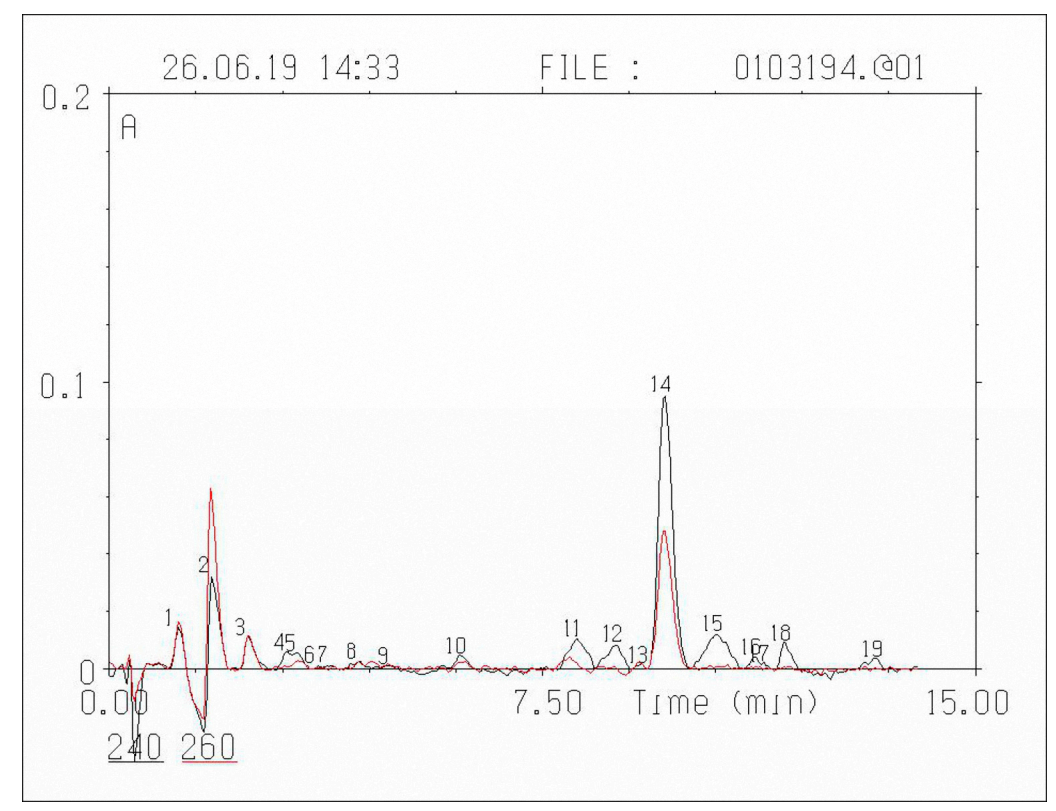

Figure 3. Chromatogram of rat blood plasma extract: the black line refers to absorption at $240 \mathrm{~nm}$, the red line is absorption at $260 \mathrm{~nm}$; N12-11-dehydrocorticosterone; N14-corticosterone.

Activities of $11 \beta H S D-2$ were measured according to [29]. Pieces of the renal cortex of 25-30 mg were weighed and were placed into a cooled glass homogenizer. Then, one $\mathrm{mL}$ of $20 \mathrm{mM}$ Tris-HCl buffer, pH 8.3, containing $5 \mathrm{mM} \mathrm{Mg}(\mathrm{CH} 3 \mathrm{COO})_{2}, 30 \mathrm{mM} \mathrm{KCl}, 250 \mathrm{mM}$ sucrose, and $0.5 \%$ Triton X-100 was added and homogenized thoroughly. The homogenate was centrifuged at $3000 \mathrm{~g}$ for $15 \mathrm{~min}$ at $4{ }^{\circ} \mathrm{C}$ and the supernatant was used for further analysis. A total of $100 \mu \mathrm{L}$ of supernatant was incubated for $60 \mathrm{~min}$ at $37^{\circ} \mathrm{C}$ in the presence of $0.2 \mu \mathrm{M}$ corticosterone and $1.5 \mathrm{mM}$ NADP in $0.1 \mathrm{M}$ Na-phosphate 
buffer, $\mathrm{pH}$ 8.5. The reaction was stopped by the addition of $100 \mu \mathrm{L}$ of acetonitrile. Then, the incubation mixture was centrifuged and $8 \mu \mathrm{L}$ of the supernatant was analyzed by high-performance liquid chromatography (HPLC) on a "Milichrom-1" chromatograph (Nauchpribor, Russia) equipped with the analytical column $(2 \times 62 \mathrm{~mm}$, Silasorb C18, $5 \mu \mathrm{m})$. Acetonitrile gradient in water (from 30 to $55 \% v / v$ ) was used as the eluent. The detection wavelengths were 240 and $260 \mathrm{~nm}$. Chromatographic information was processed using the CHROM program (EkoNova Institute of Chromatography, CJSC, Novosibirsk, Russia). Enzymatic activity was expressed as nanomoles of 11-dehydrocorticosterone formed per one minute in one gram of tissue $\left(\mathrm{nmol} \mathrm{min} \mathrm{g}^{-1}\right)$.

Statistical analysis. Data were analyzed with the SigmaPlot 12.5. Quantitative data were presented as mean \pm SEM. Two-way ANOVA with Tukey post-hoc tests was used to compare all outcome measures between the groups. $p<0.05$ was considered significant.

\section{Conclusions}

The results of the study indicate that "fast-" and "slow metabolizers" are associated with the predominating activity of various pathways of glucocorticoid metabolism. In fast metabolizers, the CYP3A-dependent pathway is activated, and in slow metabolizers, the 11ßHSD-2 pathway. Our data additionally confirm the activation of the $11 \beta \mathrm{HSD}-2$ pathway in experimental PTSD, while the resistance to PTSD can be associated with the activation of CYP3A-dependent glucocorticoid metabolism.

Author Contributions: All authors contributed to the study concept and the study design. M.K., O.C., P.P., S.F., D.T., and V.K. performed laboratory studies and data collection. O.T., V.T., and P.S. performed data analysis and interpretation. E.M., A.S., and M.K. drafted the manuscript. H.F.D. and A.S. provided critical revisions. All authors have read and agreed to the published version of the manuscript.

Funding: This work was supported by Russian Science Foundation 17-15-013418 and in part by the contracts of the ministry of Education and Science of the Russian Federation with South Ural State University (17.7255.2017/8.9) and Institute of Immunology and Physiology (AAAA-A18-118020690020-1).

Acknowledgments: The authors would like to thank Denis Kozochkin and Daria Popova for the methodological and laboratory help.

Conflicts of Interest: The authors declare no conflict of interest.

\section{Abbreviations}

$\begin{array}{ll}\text { 11Dehydro Cor } & \text { 11-dehydrocorticosterone (endogenous corticosteroid) } \\ \text { 11ßHSD-2 } & \text { 11ß-hydroxysteroid dehydrogenase type 2 (enzyme) } \\ 6 \beta \text { Cort } & \text { 6eta-hydroxycorticosterone (endogenous corticosteroid) } \\ \text { anxiety index } & \text { analysis of variance (collection of statistical models) } \\ \text { cytochrome P450 (enzyme) } \\ \text { CYN3A } & \text { ethylenediaminetetraacetic acid (chemical) } \\ \text { EDTA } & \text { elevated plus maze test } \\ \text { EPM } & \text { fast metabolizers } \\ \text { FM } & \text { high performance liquid chromatography (method). } \\ \text { HPLC } & \text { hexobarbital sleep test } \\ \text { HST } & \text { predator scent stress } \\ \text { PSS } & \text { posttraumatic stress disorder } \\ \text { PTSD } & \text { slow metabolizers } \\ \text { SM } & \end{array}$

\section{References}

1. Pitman, R.K.; Rasmusson, A.M.; Koenen, K.C.; Shin, L.M.; Orr, S.P.; Gilbertson, M.W.; Milad, M.R.; Liberzon, I. Biological studies of post-traumatic stress disorder. Nat. Rev. Neurosci. 2012, 13, 769-787. [CrossRef]

2. Yehuda, R.; Seckl, J. minireview: Stress-related psychiatric disorders with low cortisol levels: A metabolic hypothesis. Endocrinology 2011, 152, 4496-4503. [CrossRef] 
3. Kessler, R.C.; Sonnega, A.; Bromet, E.; Hughes, M.; Nelson, C.B. Posttraumatic stress disorder in the National Comorbidity Survey. Arch. Gen. Psychiatry 1995, 52, 1048-1060. [CrossRef]

4. Tseilikman, O.B.; Kozochkin, D.A.; Manukhina, E.B.; Downey, H.F.; Misharina, M.E.; Komelkova, M.V.; Nikitina, A.A.; Golodnii, S.V.; Dodohova, M.A.; Tseilikman, V.E. Predicting anxiety responses to halogenated glucocorticoid drugs using the hexobarbital sleep time test. Stress 2016, 19, 390-394. [CrossRef]

5. Wilson, A.M.; McFarlane, L.C.; Lipworth, B.J. Effects of low and high doses of inhaled flunisolide and triamcinolone acetonide on basal and dynamic measures of adrenocortical activity in healthy volunteers. J. Clin. Endocrinol. Metab. 1998, 83, 922-925. [CrossRef]

6. McEwen, B.S. Neurobiological and Systemic Effects of Chronic Stress. Chronic Stress 2017, 1. [CrossRef] [PubMed]

7. Manukhina, E.B.; Tseilikman, V.E.; Tseilikman, O.B.; Komelkova, M.V.; Kondashevskaya, M.V.; Goryacheva, A.V.; Lapshin, M.S.; Platkovskii, P.O.; Alliluev, A.V.; Downey, H.F. Intermittent hypoxia improves behavioral and adrenal gland dysfunction induced by posttraumatic stress disorder in rats. J. Appl. Physiol. 2018, 125, 931-937. [CrossRef] [PubMed]

8. Tseilikman, V.E.; Kozochkin, D.A.; Manukhina, E.B.; Downey, H.F.; Tseilikman, O.B.; Misharina, M.E.; Nikitina, A.A.; Komelkova, M.V.; Lapshin, M.S.; Kondashevskaya, M.V.; et al. Duration of hexobarbital-induced sleep and monoamine oxidase activities in rat brain: Focus on the behavioral activity and on the free-radical oxidation. Gen. Physiol. Biophys. 2016, 35, 175-183. [CrossRef] [PubMed]

9. Dremencov, E.; Lapshin, M.; Komelkova, M.; Alliluev, A.; Tseilikman, O.; Karpenko, M.; Pestereva, N.; Manukhina, E.; Downey, H.F.; Tseilikman, V. Chronic predator scent stress alters serotonin and dopamine levels in the rat thalamus and hypothalamus, respectively. Gen. Physiol. Biophys. 2019, 38, 187-190. [CrossRef]

10. Zoladz, P.R.; Conrad, C.D.; Fleshner, M.; Diamond, D.M. Acute episodes of predator exposure in conjunction with chronic social instability as an animal model of post-traumatic stress disorder. Stress 2008, 11, 259-281. [CrossRef]

11. Danan, D.; Matar, M.A.; Kaplan, Z.; Zohar, J.; Cohen, H. Blunted basal corticosterone pulsatility predicts post-exposure susceptibility to PTSD phenotype in rats. Psychoneuroendocrinology 2018, 87, $35-42$. [CrossRef] [PubMed]

12. Wilson, C.B.; McLaughlin, L.D.; Nair, A.; Ebenezer, P.J.; Dange, R.; Francis, J. Inflammation and oxidative stress are elevated in the brain, blood, and adrenal glands during the progression of post-traumatic stress disorder in a predator exposure animal model. PLoS ONE 2013, 8, e76146. [CrossRef] [PubMed]

13. Cohen, H.; Zohar, J.; Gidron, Y.; Matar, M.A.; Belkind, D.; Loewenthal, U.; Kozlovsky, N.; Kaplan, Z. Blunted HPA axis response to stress influences susceptibility to posttraumatic stress response in rats. Biol. Psychiatry 2006, 59, 1208-1218. [CrossRef] [PubMed]

14. Yehuda, R. Sensitization of the hypothalamic-pituitary-adrenal axis in posttraumatic stress disorder. Ann. N. Y. Acad. Sci. 1997, 821, 57-75. [CrossRef] [PubMed]

15. Draper, N.; Stewart, P.M. 11beta-hydroxysteroid dehydrogenase and the pre-receptor regulation of corticosteroid hormone action. J. Endocrinol. 2005, 186, 251-271. [CrossRef] [PubMed]

16. Pal'chikova, N.A.; Kuznetsova, N.V.; Selyatitskaya, V.G.; Cherkasova, O.P.; Kuz'mina, O.I. Effects of Intraperitoneal Administration of Mifepristone on Glucocorticoid Status of Experimental Animals. Bull. Exp. Biol. Med. 2016, 161, 257-260. [CrossRef]

17. Silverman, M.N.; Sternberg, E.M. Glucocorticoid regulation of inflammation and its behavioral and metabolic correlates: From HPA axis to glucocorticoid receptor dysfunction. Ann. N. Y. Acad. Sci. 2012, 1261, 55-63. [CrossRef]

18. Stranahan, A.M.; Arumugam, T.V.; Mattson, M.P. Lowering corticosterone levels reinstates hippocampal brain-derived neurotropic factor and Trkb expression without influencing deficits in hypothalamic brain-derived neurotropic factor expression in leptin receptor-deficient mice. Neuroendocrinology 2011, 93, 58-64. [CrossRef]

19. Tseilikman, V.; Komelkova, M.; Lapshin, M.; Alliluev, A.; Tseilikman, O.; Karpenko, M.; Pestereva, N.; Manukhina, E.; Downey, H.F.; Kondashevskaya, M.; et al. High and low anxiety phenotypes in a rat model of complex post-traumatic stress disorder are associated with different alterations in regional brain monoamine neurotransmission. Psychoneuroendocrinology 2020, 117, 104691. [CrossRef]

20. Sarapultsev, A.; Sarapultsev, P.; Dremencov, E.; Komelkova, M.; Tseilikman, O.; Tseilikman, V. Low glucocorticoids in stress-related disorders: The role of inflammation. Stress 2020, 1-11. [CrossRef] 
21. Tseylikman, O.B.; Lapshin, M.S.; Kozochkin, D.A.; Komel'kova, M.V.; Kuzina, O.V.; Golodniy, S.V.; Lazuko, S.S.; Tseylikman, V.E. Behavioral Activity and Some Markers of Posttraumatic Stress Disorder among Serotoninergic System Indicators and Glucocorticoid Metabolizing Enzymes in Rats with Different Duration of Hexenal Sleep. Bull. Exp. Biol. Med. 2016, 161, 456-459. [CrossRef] [PubMed]

22. Kozochkin, D.A.; Manukhina, E.B.; Downey, H.F.; Tseilikman, O.B.; Komelkova, M.V.; Vasilyeva, M.V.; Lapshin, M.S.; Sahabutdinov, M.N.; Lazuko, S.S.; Tseilikman, V.E. The role of microsomal oxidation in the regulation of monoamine oxidase activity in the brain and liver of rats. Gen. Physiol. Biophys. 2017, 36, 455-464. [CrossRef] [PubMed]

23. Breslau, N. The epidemiology of posttraumatic stress disorder: What is the extent of the problem? J. Clin. Psychiatry 2001, 62 (Suppl. 17), 16-22. [PubMed]

24. Lazuko, S.S.; Kuzhel, O.P.; Belyaeva, L.E.; Manukhina, E.B.; Fred Downey, H.; Tseilikman, O.B.; Komelkova, M.V.; Tseilikman, V.E. Posttraumatic Stress Disorder Disturbs Coronary Tone and Its Regulatory Mechanisms. Cell. Mol. Neurobiol. 2018, 38, 209-217. [CrossRef] [PubMed]

25. Lapiz-Bluhm, M.D.S.; Bondi, C.O.; Doyen, J.; Rodriguez, G.A.; Bédard-Arana, T.; Morilak, D.A. Behavioural Assays to Model Cognitive and Affective Dimensions of Depression and Anxiety in Rats. J. Neuroendocrinol. 2008, 20, 1115-1137. [CrossRef] [PubMed]

26. Serova, L.I.; Tillinger, A.; Alaluf, L.G.; Laukova, M.; Keegan, K.; Sabban, E.L. Single intranasal neuropeptide $\mathrm{Y}$ infusion attenuates development of PTSD-like symptoms to traumatic stress in rats. Neuroscience 2013, 236, 298-312. [CrossRef]

27. Cohen, H.; Matar, M.A.; Joseph, Z. Animal models of post-traumatic stress disorder. Curr. Protoc. Neurosci. 2013. Chapter 9. [CrossRef]

28. Selyatitskaya, V.G.; Cherkasova, O.P.; Pankina, T.V.; Palchikova, N.A. Functional state of adrenocortical system in rats with manifest alloxan-induced diabetes mellitus. Bull. Exp. Biol. Med. 2008, 146, 708-710. [CrossRef]

29. Cherkasova, O.P. Activity of $11 \beta$-hydroxysteroid dehydrogenase of rat kidney and liver in inherited stress-induced arterial hypertension. Biochem. Moscow Suppl. Ser. B 2007, 1, 172-175. [CrossRef]

(C) 2020 by the authors. Licensee MDPI, Basel, Switzerland. This article is an open access article distributed under the terms and conditions of the Creative Commons Attribution (CC BY) license (http://creativecommons.org/licenses/by/4.0/). 